\title{
Case Series of Hemophagocytic Lymphohistiocytosis from a Tertiary Care Centre: An Underdiagnosed Entity
}

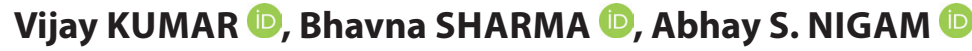 \\ Department of Pathology, PGIMER, Dr. Ram Manohar Lohia Hospital, NEW DELHI, INDIA
}

\begin{abstract}
Objective: Hemophagocytic Lymphohistiocytosis (HLH) is an uncommon, life-threatening hyperinflammatory syndrome, caused by severe hypercytokinemia, due to an overstimulated but ineffective immune process. The presenting features of HLH are non-specific, mimicking many other diseases, and hence its early recognition still remains a challenge. It requires a high index of suspicion and detailed analysis of clinical and laboratory findings to arrive at a conclusive diagnosis. The objective of this study is to present detailed clinical and laboratory features of a series of HLH cases.
\end{abstract}

Material and Method: A retrospective study was conducted wherein all the bone marrow aspirate smears diagnosed as HLH between January 2015 to June 2018 were reviewed. Detailed correlation of clinical and laboratory criteria was done with the bone marrow findings.

Results: A total of twelve cases were diagnosed as HLH from January 2015 to June 2018. Ten patients fulfilled 5 out of 8 clinical and lab diagnostic criteria of HLH (2004). After correlating clinical and laboratory criteria along with bone marrow findings the diagnosis of HLH was suggested.

Conclusion: We present a series of twelve cases of Hemophagocytic Lymphohistiocytosis from a tertiary care hospital in New Delhi which will add not only to the understanding of this rare life threatening disease but also to the early diagnosis and intervention.

Key Words: Hemophagocytosis, Lymphohistiocytosis, Hyperferritinemia, Pancytopenia

\section{INTRODUCTION}

The first case of hemophagocytic lymphohistiocytosis (HLH) was reported in 1952 by Farquhar and Claireaux, who named it familial hemophagocyticreticulosis (1). HLH represents a hyperinflammatory, uncontrolled immune response caused by various stimuli (2). The disease primarily affects pediatric age group but adults are also commonly involved (3). It is of two types- genetic and acquired. The basic defect in both genetic and acquired cases lies in the NK/T cell cytotoxic pathway. This leads to inability of NK/T cells to kill activated macrophages, which in turn leads to uncontrolled proliferation of activated macrophages (3). Genetic cases can be further divided into familial and those associated with an immunodeficiency syndrome (4). Familial HLH is of five types with mutations in various proteins involved in packaging, transport and release of cytolytic granules, namely Perforin 1, UNC13D, STX11 and STXB2. The common immunodeficiency syndromes associated with HLH are Chediak Higashi syndrome, Griscelli syndrome, Hermansky Pudlak syndrome and $\mathrm{X}$ linked lymphoproliferative syndrome (4). Acquired cases can be broadly secondary to infections/ malignancy/ rheumatologic causes (4). Macrophage

(Turk Patoloji Derg 2019, 35:207-212)

Received : 14.01.2019 Accepted : 06.03.2019 activation syndrome (MAS) is usually associated with rheumatologic diseases like systemic-onset juvenile idiopathic arthritis (SOJIA), adult-onset Still disease, and systemic lupus erythematosus $(5,6)$.

Diagnostic criteria for HLH were proposed in 1991 and updated in $2004(7,8)$. The 2004 criteria are as follows. The diagnosis requires the presence of either criterion A or 5 out of 8 of criterion B.

Diagnostic criteria for HLH (2004)

A. Familial disease/known genetic defect

OR

B. Clinical/laboratory criteria

1. Fever,

2. Splenomegaly,

3. Cytopenia (at least 2 cell lines)

HGB $<9$ gram/dL,

PLT $<100,000 /$ microL,

ANC $<1000 /$ microL 
4. Hypertryglyceridemia and/or hypofibrinogenemia, Fasting triglyceride $>265 \mathrm{mg} / \mathrm{dL}$, Fibrinogen $<150 \mathrm{mg} / \mathrm{L}$,

5. Hyperferritinemia, Ferritin $>500 u g / 1$

6. Hemophagocytosis in bone marrow, CSF, or lymph nodes,

7. Decreased/absent NK cell activity

8. Soluble CD25 > $2400 \mathrm{U} / \mathrm{ml}$.

\section{MATERIALS and METHODS}

We conducted a retrospective study in the department of pathology, PGIMER, Dr. Ram Manohar Lohia Hospital, Delhi. All the bone marrow aspirate smears diagnosed as HLH between January 2015 to June 2018 were reviewed.
The requisition forms of the same were reviewed to get all relevant clinical and laboratory details. Bone marrow smear findings were correlated with clinical and laboratory findings.

\section{RESULTS}

A total of twelve cases were diagnosed as HLH from January 2015 to June 2018. The clinical features and laboratory findings of patients are summarized in Table I and II. All bone marrow smears, except one, showed increased number of histiocytes, with features of hemophagocytosis (Figure 1A-D). The age of the patients ranged from 3 months to 65 years (male: female $=2: 1$ ). All patients presented with fever and cytopenia, one had pancytopenia, eight had bicytopenia, one had only anemia and two did
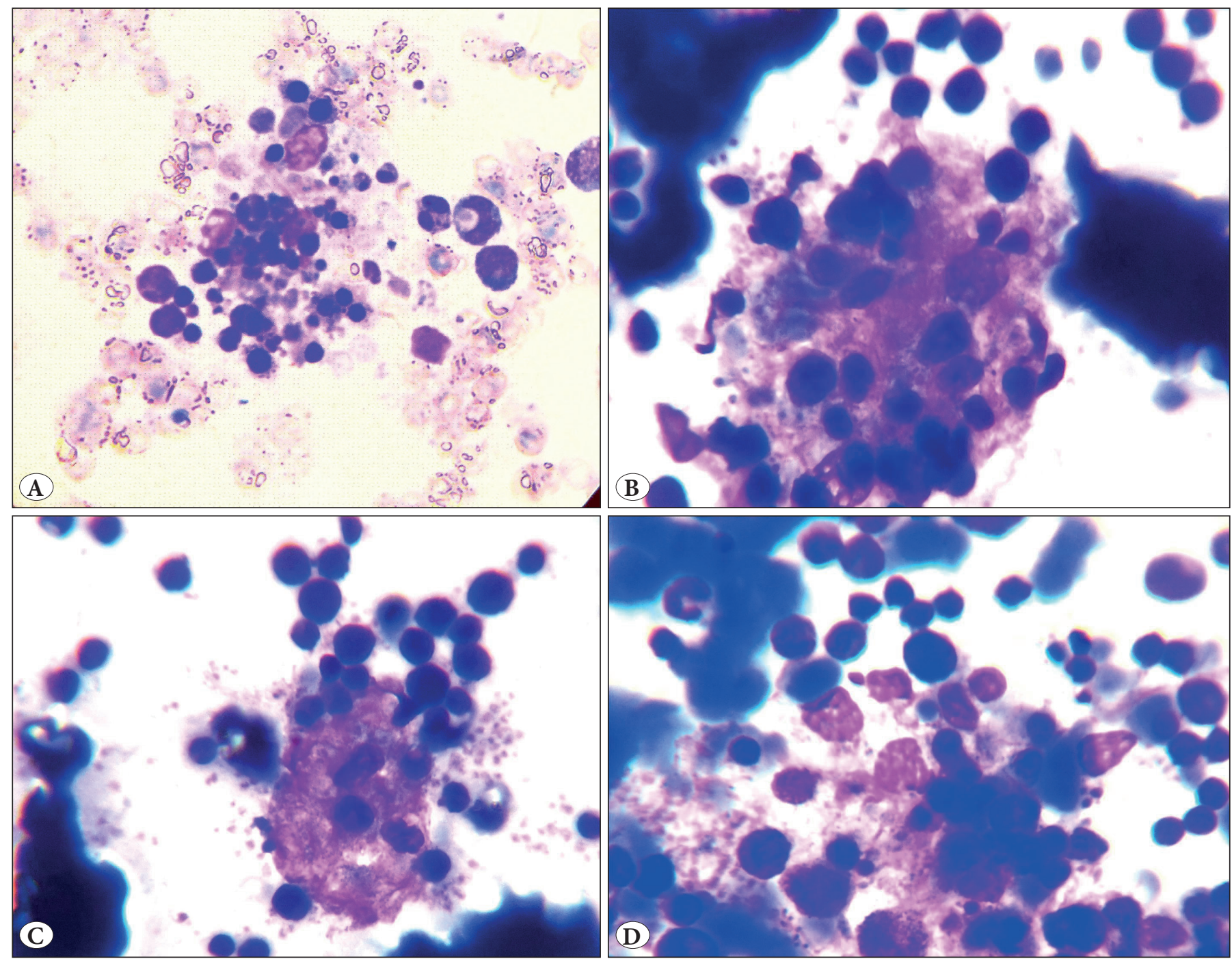

Figure 1: A) Bone marrow aspirate showing two histiocytes with phagocytosed debris in cytoplasm (Giemsa; x200). B) High power view of histiocyte in bone marrow aspirate with phagocytosed hematopoetic cells in cytoplasm (Giemsa; x1000). C) Bone marrow aspirate with histiocyte showing phagocytosed neutrophils in cytoplasm (Giemsa; x1000). D) Bone marrow aspirate with histiocyte showing phagocytosed erythroid series cells in cytoplasm (Giemsa; x1000). 
not have any cytopenia. The etiological spectrum primarily included infections and autoimmune disease. None of the cases was malignancy related. Four patients had history of systemic onset juvenile idiopathic arthritis (out of which one was positive for both parvovirus and rickettsia), two had undifferentiated connective tissue disease (out of which one had tuberculosis and the other one had past history of macrophage activation syndrome), one was a known case of SLE, one was hepatitis B +ve, one typhidot positive, one CMV positive and one was a suspected case of dengue. Ten patients fulfilled 5 out of 8 clinical and lab diagnostic criteria of HLH (2004). The two patients who did not fulfill five criteria were diagnosed as HLH because of strong clinical suspicion. One of these had past history of MAS with present bone marrow showing prominent hemophagocytosis and the other one also similarly demonstrated extensive hemophagocytosis on bone marrow biopsy (Figure 2). After correlating clinical

Table I: Laboratory features of patients.

\begin{tabular}{lccccccc}
\hline Age/Gender & Cytopenia & S.TG & $\begin{array}{c}\text { Fibrinogen } \\
\mathbf{n g} / \mathbf{m l}\end{array}$ & $\begin{array}{c}\text { S. ferritin } \\
\mathbf{n g} / \mathbf{m l}\end{array}$ & LDH & BMA HPG & Etiology \\
\hline $\mathbf{5 / F}$ & Bicytopenia & 350 & 417 & 6024 & 800 & + & LAC, ACL+ \\
\hline $\mathbf{1 6 / \mathbf { M }}$ & Bicytopenia & 441 & NA & NA & 2350 & + & Typhidot+ \\
\hline $\mathbf{1 . 5 / M}$ & Bicytopenia & 1223 & NA & NA & 2504 & + & - \\
\hline $\mathbf{3 6 / M}$ & Bicytopenia & 818 & NA & 13264 & 1687 & - & Suspected dengue \\
\hline $\mathbf{7 / F}$ & Pancytopenia & 295 & NA & NA & NA & + & SOJIA \\
\hline $\mathbf{6 5 / M}$ & Bicytopenia & 303 & NA & 3200 & 2377 & + & HbsAg+ \\
\hline $\mathbf{1 4 / M}$ & - & 350 & NA & NA & NA & ++ & Undiff CTD, TB \\
\hline $\mathbf{1 0 / F}$ & - & NA & NA & NA & NA & ++ & Undiff CTD h/o MAS \\
\hline 7/M & Bicytopenia & 346 & NA & 600 & 820 & + & Parvo, Rickettsia, SOJIA \\
\hline $\mathbf{5 / M}$ & Bicytopenia & 461 & 250 & NA & 876 & + & SOJIA \\
\hline $\mathbf{6 / F}$ & Bicytopenia & NA & NA & 2000 & NA & + & SOJIA \\
\hline $\mathbf{3 m o / M}$ & Anemia & N & 230 & 61679 & 22500 & + & CMV \\
\hline
\end{tabular}

S. TG: Serum triglycerides, LDH: Lactate dehydrogenase, BMA HPG: Bone marrow aspirate hemophagocytosis, LAC: Lupus anticoagulant, ACL: Anticardiolipin, SOJIA: Systemic onset juvenile idiopathic arthritis, CTD: Connective tissue disease.
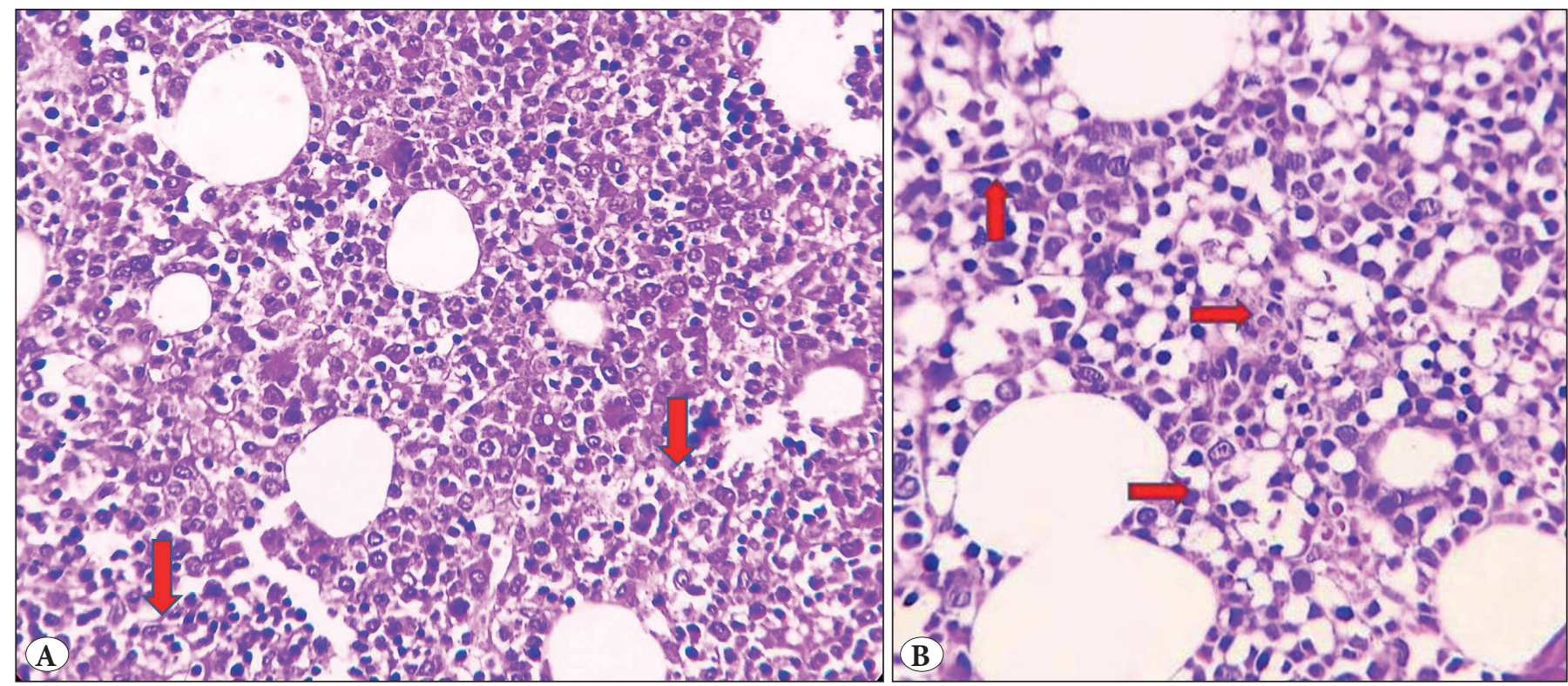

Figure 2: A) Bone marrow biopsy showing many foamy histiocytes with hemophagocytosis (H\&E; x100). B) High power view of hemophagocytosis in bone marrow biopsy showing histiocytes with phagocytosed hemopoietic cells in the cytoplasm (H\&E; x200). 
Table II: Clinical features of patients.

\begin{tabular}{|c|c|c|c|c|c|c|c|c|}
\hline Age/Gender & Fever & Arthritis & Rash & Jaundice & Neurologic & Shock & Hepatomegaly & Splenomegaly \\
\hline $5 / \mathrm{F}$ & + & + & + & - & - & - & - & - \\
\hline $16 / \mathrm{M}$ & + & - & - & - & - & - & + & + \\
\hline $36 / \mathrm{M}$ & + & - & + & + & - & - & + & + \\
\hline $7 / \mathrm{F}$ & + & + & - & + & + & + & + & + \\
\hline $14 / \mathrm{M}$ & + & + & - & - & - & - & - & + \\
\hline $10 / \mathrm{F}$ & + & + & - & - & - & - & + & - \\
\hline $7 / \mathrm{M}$ & + & + & - & - & - & - & - & - \\
\hline $5 / \mathrm{M}$ & + & + & - & - & - & - & + & + \\
\hline
\end{tabular}

and laboratory criteria along with bone marrow findings, the diagnosis of HLH was suggested.

\section{DISCUSSION}

The knowledge about the profile of HLH in the Indian subcontinent is limited despite the disease being life threatening, and is available in the form of few case series (9-14). The age range in our series varied from 3 months to 65 years (mean age 14 years). This is similar to the series of five cases reported by Reddy et al. (mean age 17 years) (9). The male to female ratio in the present series was 2:1. Reddy et al. similarly found a male preponderance (M:F 4:1) whereas Joshi et al. found a female preponderance (M:F 1:4) (9,11). The most frequent presenting symptom was fever with cytopenia and hepatosplenomegaly. Joshi et al. in their case series from Mumbai also concluded that HLH should be suspected in any patient experiencing unresolving fever with cytopenia and hepatosplenomegaly (11). Similarly Ramachandran et al. also found fever and hepatosplenomegaly as the most common presenting complaint in their case series of 33 pediatric patients (12). Only one patient presented acutely with neurologic symptoms in the form of abnormal body movements and shock. This was a 7-year-old female, a known case of SOJIA, and was diagnosed as MAS. We found CNS involvement in only one patient (8\%) which is in contrast to Joshi et al. (30\%), Ramachandaran et al. (36\%), and Reddy et al. $(80 \%)(9,11,12)$. Ferritin levels were available at the time of diagnosis in 6/12 patients, LDH in $8 / 12$, serum triglycerides in $9 / 12$ and serum fibrinogen in $3 / 12$ patients. Hyperferritenemia, raised $\mathrm{LDH}$ and raised triglycerides (according to the HLH 2004 criteria) were found in all these patients. However, low fibrinogen was observed in $2 / 3$ patients only.

We could determine the underlying etiology in 11/12 patients. An infectious cause was found in $6 / 12$ patients (50\%) [1-CMV, 1 -Dengue, 1- hepatitis B, 1- Typhoid, 1-TB, 1- Rickettsia]. Ramachandran et al. similarly found an infectious cause in $42 \%$ of the pediatric patients and Joshi et al. in $30 \%$ of the patients $(11,12)$. Out of the infectious causes, the most commonly responsible ones are viral\{EBV, CMV, parvovirus] followed by bacterial [Brucella, TB], parasitic [Leishmaniasis] and fungal infections $(15,16)$. One of the patient in the present series was a suspected case of uncomplicated dengue fever who presented with fever and macular rash on the abdomen [third day of fever] along with anemia and thrombocytopenia. Dengue virus is a very uncommon cause of HLH with most of the reported cases being associated with complicated hemorrhagic cases (17-19). However, our case was of uncomplicated dengue as has been previously reported once (20). This patient had very high levels of ferritin, $\mathrm{LDH}$, triglycerides and was thus diagnosed to have HLH, even though the bone marrow failed to reveal hemophagocytosis. Hemophagocytosis may not be evident in very early stages of $\mathrm{HLH}$, and thus its absence does not negate the diagnosis of HLH (21). The incidence of bone marrow involvement varies between $25 \%$ and $100 \%$ (22). This implies that the diagnosis of HLH requires a comprehensive clinical, biochemical and hematological approach.

HLH is a diagnostic challenge to clinicians as its presenting signs and symptoms are non specific and thus portend a wide array of differential diagnoses. The presenting signs 
involve multiple organs and hence multiorgan disorders like sepsis, MODS, etc. come into close differentials. It has been found that cytopenias and extremely high ferritin levels are most helpful in diagnosing HLH (3). The closest differential in pediatric patients is sepsis. Palazzi et al. in their series of pediatric PUO patients found that very high levels of ferritin and LDH were highly suggestive of HLH (23). Other differentials include multiple organ dysfunction syndrome [MODS], liver failure, and encephalitis. Again increasing levels of ferritin, high $\mathrm{LDH}$ and cytopenias accompanied by evidence of bone marrow hemophagocytosis help in clinching the diagnosis (3). For familial HLH the only confirmatory test is genetic testing for mutations, the most common being mutations in the perforin gene (3). However, this is available in only limited laboratories. Recently, flow cytometry for perforin expression has been introduced for screening of HLH. It can prove to be useful as it is economical and readily available (24).

It is difficult to establish a preset diagnostic approach for reaching the right diagnosis. Most of the patients are seriously ill and present with signs and symptoms pertaining to multiple organs, i.e. central nervous system abnormalities, liver function dysfunction, bone marrow insufficiency, immune dysfunction, etc. Sometimes all the criteria for HLH are not met but a high index of suspicion is required for the diagnosis of such cases in the initial stages. All patients with prolonged fever and cytopenias must be evaluated for HLH by obtaining a detailed history, performing a detailed physical examination and by using the relevant biochemical tests. The history should aim at finding out the underlying etiology, so the patient should be asked about pre-existing viral illness, fever to rule out infectious causes, history of fever with joint pains to rule out underlying autoimmune joint disease and history of significant weight loss and any other symptoms for underlying malignancy. The physical examination should include detailed search for lymphadenopathy, hepatosplenomegaly, and complete examination of all the organ systems. In addition laboratory tests should be ordered to confirm the suspected etiology like complete blood count and blood, urine, CSF culture to establish infective cause, and CT neck, abdomen, etc. to rule out malignant etiology, etc. Additional tests like ferritin, triglycerides, LDH and fibrinogen will confirm the diagnosis. Bone marrow examination should be done and diligently searched for hemophagocytosis. Cr release assays to measure NK cell activity and measurement of sCD25 are also helpful to arrive at the diagnosis; however, these tests are not readily available and hence cannot be relied upon. It is imperative to differentiate genetic $\mathrm{HLH}$ from secondary HLH as the latter is treatable by finding the underlying cause. Management of secondary HLH cases includes antiviral agents for virus associated cases, antibiotics, antiparasitic drugs, and antifungal agents for bacterial, parasitic and fungus associated cases respectively. For genetic HLH, stem cell transplantation is the only effective therapy.

The 2004 HLH treatment protocol by the Histiocyte Society recommends use of 8 weeks of induction therapy of cyclosporine, etoposide and corticosteroids (25). Permanent cure is possible only with stem cell transplantation but treatment of the underlying cause is indicated for acquired HLH. In the present series, all the patients diagnosed as HLH were treated with corticosteroids. In addition, antiviral agents were given in the cases found to be positive for CMV and Parvovirus, and ceftriaxone was given to the case found to be typhidot positive. All the patients were followed for a period of two months following which all showed improvement and were ultimately discharged.

The prognosis of genetic HLH is dismal (25). The prognosis of acquired HLH is variable depending on the underlying cause, with malignancy associated cases having the worst outcome (26).

In conclusion, HLH is an uncommon, fatal but underdiagnosed disease. The symptoms of the disease are non specific, mimicking many conditions and hence requires a high index of suspicion for making a timely diagnosis. In view of the paucity of data from the Indian subcontinent, this study is an attempt for better understanding and early diagnosis of the disease as it will pave the way for better management of the patients.

\section{CONFLICT of INTEREST}

The authors declare no conflict of interest.

\section{FUNDING}

None

\section{REFERENCES}

1. Farquhar JW, Claireaux AE. Familial haemophagocyticreticulosis. Arch Dis Child. 1952;27:519-25.

2. Janka GE. Familial and acquired hemophagocytic lymphohistiocytosis. Annu Rev Med. 2012;63:233-46.

3. McClain K. Clinical features and diagnosis of hemophagocytic lymphohistiocytosis. Up To Date - Topic 87499 Version 1.0

4. Rosado FG, Kim AS. Hemophagocytic lymphohistiocytosis: An update on diagnosis and pathogenesis. Am J Clin Pathol. 2013;139:713-27. 
5. Parodi A, Davì S, Pringe AB, Pistorio A, Ruperto N, MagniManzoni S, Miettunen P, Bader-Meunier B, Espada G, Sterba G, Ozen S, Wright D, Magalhães CS, Khubchandani R, Michels $\mathrm{H}$, Woo P, Iglesias A, Guseinova D, Bracaglia C, Hayward K, Wouters C, Grom A, Vivarelli M, Fischer A, Breda L, Martini A, Ravelli A; Lupus Working Group of the Paediatric Rheumatology European Society. Macrophage activation syndrome in juvenile systemic lupus erythematosus: A multinational multicenter study of thirty-eight patients. Arthritis Rheum. 2009;60:3388-99.

6. Deane S, Selmi C, Teuber SS, Gershwin ME. Macrophage activation syndrome in autoimmune disease. Int Arch Allergy Immunol. 2010;153:109-20.

7. Henter JI, Elinder G, Söder O, Ost A. Incidence in Sweden and clinical features of familial hemophagocytic lymphohistiocytosis. Acta Paediatr Scand. 1991;80:428-35.

8. Henter JI, Horne A, Aricó M, Egeler RM, Filipovich AH, Imashuku S, Ladisch S, McClain K, Webb D, Winiarski J, Janka G. HLH2004: Diagnostic and therapeutic guidelines for hemophagocytic lymphohistiocytosis. Pediatr Blood Cancer. 2007;48:124-31.

9. Reddy S, Rangappa P, Kasaragod A, Kumar AS, Rao K. Haemophagocytic lymphohistiocytosis (HLH): Case series in tertiary referral hospital over three years. J Assoc Physicians India. 2013;61:850-2.

10. Rajagopala S, Singh N, Agarwal R, Gupta D, Das R. Severe hemophagocytic lymphohistiocytosis in adults-experience from an intensive care unit from North India. Indian J Crit Care Med. 2012;16:198-203.

11. Joshi R, Phatarpekar A, Currimbhoy Z, Desai M. Haemophagocytic lymphohistiocytosis: A case series from Mumbai. Ann Trop Paediatr. 2011;31:135-40.

12. Ramachandran B, Balasubramanian S, Abhishek N, Ravikumar KG, Ramanan AV.Profile of hemophagocyticlymphohistiocytosis in children in a tertiary care hospital in India. Indian Pediatr. 2011;48:31-5.

13. Gopal GK, Anugrah C, Boorugu H. Scrub typhus associated macrophage activation syndrome. Trop Doct. 2010;40:249-50.

14. Rajagopala S, Dutta U, Chandra KS, Bhatia P, Varma N Kochhar R. Visceral leishmaniasis associated hemophagocytic lymphohistiocytosis-case report and systematic review. J Infect. 2008;56:381-8.
15. Risdall RJ, Brunning RD, Hernandez JI, Gordon DH. Bacteria associated hemophagocytic syndrome. Cancer. 1984;54:2968-72.

16. Sung PS, Kim IH, Lee JH, Park JW. Hemophagocytic Lymphohistiocytosis (HLH) Associated with Plasmodium vivax Infection: Case report and review of the literature. Chonnam Med J. 2011;47:173-6.

17. Ramanathan M, Duraisamy G. Haemophagocytosis in dengue haemorrhagic fever: A case report. Ann Acad Med Singapore. 1991;20:803-4.

18. Rueda E, Mendez A, Gonzalez G. Hemophagocytic syndrome associated with dengue hemorrhagic fever. Biomedica. 2002;22:160-6.

19. Lu PL, Hsiao HH, Tsai JJ, Chen TC, Feng MC, Chen TP, Lin SF. Dengue virus associated hemophagocytic syndrome and dyserythropoiesis: A case report. Kaohsiung J Med Sci. 2005;21:34-9.

20. Jain D, Singh T. Dengue virus related hemophagocytosis: A rare case report. Hematology. 2008;13:286-8.

21. Gupta A, Tyrell P, Valani R, Benseler S, Weitzman S, Abdelhaleem $\mathrm{M}$. The role of the initial bone marrow aspirate in the diagnosis of hemophagocytic lymphohistiocytosis. Pediatr Blood Cancer. 2008:51:402-4.

22. Siddaiahgari SR, Agarwal S, Madukuri P, Moodahadu LS. Hemophagocytic Lymphohistiocytosis: A Review. J Blood Disord Transfus. 2016;7:363.

23. Palazzi DL, McClain KL, Kaplan SL. Hemophagocytic syndrome in children: An important diagnostic consideration in fever of unknown origin. Clin Infect Dis. 2003;36:306-12.

24. Kogawa K, Lee SM, Villanueva J, Marmer D, Sumegi J, Filipovich AH. Perforin expression in cytotoxic lymphocytes from patients with hemophagocytic lymphohistiocytosis and their family members. Blood. 2002;99:61-6.

25. Henter JI, Samuelsson-Horne A, Aricò M, Egeler RM, Elinder G Filipovich AH, Gadner H, Imashuku S, Komp D, Ladisch S, Webb D, Janka G; Histocyte Society. Treatment of hemophagocytic lymphohistiocytosis with HLH-94 immunochemotherapy and bone marrow transplantation. Blood. 2002;100:2367-73.

26. Janka G, zur Stadt U. Familial and acquired hemophagocytic lymphohistiocytosis. Hematol Am Soc Hematol Educ Program. 2005:82-8. 